\section{Dielectric Properties of Titanates at Ultra-high Frequencies}

THE complex permittivity $\left(x^{\prime}-j x^{\prime \prime}\right)$ of a series of titanates, magnesium, calcium, strontium and barium, has been measured at $21^{\circ} \mathrm{C}$. and frequencies of 1.5 and $9,450 \mathrm{Mc} / \mathrm{s}$., and of the barium titanate at 24,000 Mc./s. also. In addition, the behaviour of barium titanate at 1.5 and $9,450 \mathrm{Mc} / \mathrm{s}$. has been studied over the temperature-range $+20^{\circ}$ to $+170^{\circ} \mathrm{C}$. The results of these measurements are recorded in the accompanying table and diagram. The electric field-strength applied to the test specimens was estimated as less than $l$ volt $/ \mathrm{cm}$.

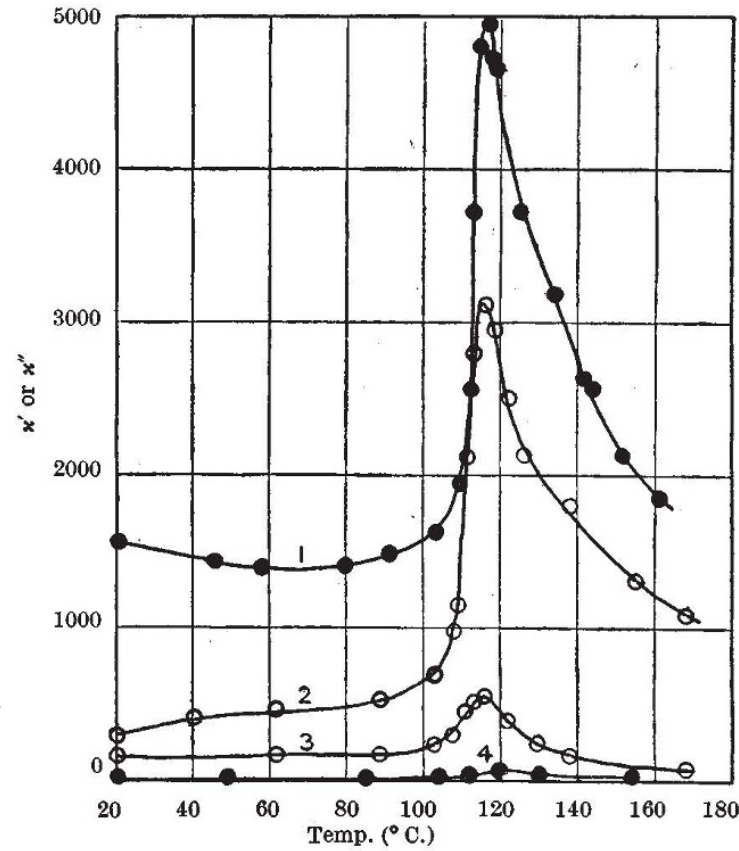

Dielectric properties of barium titanate at $1.5 \mathrm{Mc} / \mathrm{sec}$. and $9,450 \mathrm{Mc}$./sec. Curves $1, x^{\prime}$ at $1.5 \mathrm{Mc}$./sec.; $2, \boldsymbol{x}^{\prime}$ at $9,450 \mathrm{Mc}$. $/ \mathrm{sec}$. $3, x^{\prime \prime}$ at $9,450 \mathrm{Mc}$./sec.; $4, x^{\prime \prime}$ at $1 \cdot 5 \mathrm{Mc}$./sec.

The loss tangent $\left(\tan \delta=x^{\prime \prime} x^{\prime}\right)$ of the magnesium, calcium and strontium titanates at 9,450 Mc./s. was sufficiently small to permit the use of a technique, described in an earlier communication ${ }^{1}$, which con. sists in measuring the variation with frequency of the energy transmitted through a slab located in, and filling, the cross-section of a wave-guide. The attenuation in barium titanate, however, proved to be so high that this method could not be used, and the complex permittivity was determined by measurement of the reflexion from and transmission through a slab, at fixed frequency. For the reflexion measurements it was sufficient to consider only the front face of the specimen, since internal reflexions were highly attenuated. In order to reduce the power standing. wave ratio in front of the face to measurable values, quarter-wave 'matching' slabs of lower permittivity materials were used. For example, with 'Tempa $S$ ', $x^{\prime}=11 \cdot 3$, the power standing-wave ratio was reduced by $320: 1$ and with polystyrene, $x^{\prime}=2 \cdot 56$, by $17: 1$. The attenuation in the material was obtained by measurement of the transmission through specimens with matching slabs at each side. From a combination of the results of the two measurements, values of $x^{\prime}$ and $x^{\prime \prime}$ can be calculated.
At $21^{\circ} \mathrm{C}$.

\begin{tabular}{|c|c|c|c|c|c|c|}
\hline \multirow[b]{2}{*}{ Material } & \multicolumn{3}{|c|}{$x^{\prime}$} & \multicolumn{3}{|c|}{$\tan \delta=x^{\prime \prime} / x^{\prime}$} \\
\hline & $\begin{array}{c}1 \cdot 5 \\
\mathrm{Mc} . / \mathrm{s} .\end{array}$ & $\begin{array}{l}9,450 \\
\text { Mc./s. }\end{array}$ & $\begin{array}{l}24,000 \\
\text { Mc./s. }\end{array}$ & $\begin{array}{c}1 \cdot 5 \\
\text { Mc. } / \mathrm{s} .\end{array}$ & $\begin{array}{l}9,450 \\
\mathrm{Mc} / \mathrm{s} .\end{array}$ & $\begin{array}{l}24,000 \\
\mathrm{Mc} . / \mathrm{s} .\end{array}$ \\
\hline $\begin{array}{l}\mathrm{MgTiO}_{3} \\
\mathrm{CaTiO}_{3} \\
\mathrm{SrTiO}_{3}\end{array}$ & $\begin{array}{l}13 \cdot 0 \\
140 \\
264\end{array}$ & $\begin{array}{l}11 \cdot 3 \\
132 \\
232\end{array}$ & E & $\begin{array}{l}0.0012 \\
0.0007 \\
0.0009\end{array}$ & $\begin{array}{l}<0.05 \\
<0.015 \\
<0.03\end{array}$ & 二 \\
\hline $\mathrm{BaTiO}_{3}$ & 1,500 & 300 & 126 & 0.015 & 0.53 & 0.59 \\
\hline
\end{tabular}

It will be seen from the table that the room. temperature permittivity values at $9,450 \mathrm{Mc} / \mathrm{s}$. of the magnesium, calcium and strontium titanates are not appreciably different from the $1.5 \mathrm{Mc}$./s. figures, but that for barium titanate a substantial decrease has occurred at the higher frequency, and a still further decrease at 24,000 Mc./s. In keeping with these observations, while the loss tangent of the magnesium, calcium and strontium titanates does not exhibit a particularly marked increase with frequency, that of barium titanate has risen to a very high value at the two ultra-high frequencies. It has not yet been possible to extend the range of frequency measurement, but there can be no doubt of the existence of dispersion in barium titanate in this region of frequency, a fact which will be of considerable significance in the interpretation of its general behaviour.

The variable temperature measurements at $9,450 \mathrm{Mc}$./s. on barium titanate show that although the permittivity is lower throughout than at $1.5 \mathrm{Mc} . / \mathrm{s}$., the rapid rise to a peak value occurs at substantially the same temperature in the two cases.

A full report of the work will appear elsewhere; but I wish to acknowledge here the help afforded by the United Insulator Co. and the Mullard Radio Valve Co. in supplying the ceramic specimens, and to thank the Department of Scientific and Industrial Research for financial support of the work.

\section{J. G. Pownes}

Electrical Engineering Department,

Imperial College, London, S.W.7.

June 2.

${ }^{1}$ Powles, J. G., Nature, 161, 25 (1948).

\section{New Photoconductive Cells}

So far there are few substances known to possess photoconducting properties with a quantum yield appreciably greater than unity. The chief ones are selenium, oxidized thallous sulphide, and the sulphide, selenide and telluride of lead.

Two questions arise : (1) Are the above-mentioned substances the only possible ones, and, if so, what is the reason for that? (2) What is the role of the oxygen in sensitizing at least thallium and lead sulphides, lead selenide and lead telluride ?

Experiments with various types of semi-conductors suggested to me that the particular action of the oxygen can be best accounted for if it is assumed that the oxygen is adsorbed on the semi-conductor particles during evaporation and after the deposit has been formed, and not, or only partly, as a secondary process, taken up by the lattice. It is known that adsorption of gases on finely divided metals is much increased if an electric discharge is passed through the vessel containing the adsorbent ${ }^{1}$.

If the above-mentioned view is correct, methods which produce a layer of material by a process in 